\title{
Student Agency to Participate in Dialogic Science Discussions
}

\author{
Sherice N. Clarke*, Iris Howley, Lauren Resnick \& Carolyn Penstein Rosé
}

\begin{abstract}
Students enter learning situations (informal and formal alike) with a wealth of knowledge, skill and expertise with which to engage in new learning experiences. However, in dialogic science discussions, many students do not call on these resources to engaging in discussion, and some students rarely participate. In this paper, we introduce a hybrid model of agency as a lens to examine the enablers and barriers to students' engagement in dialogic science discussions. We operationalize this model in the analysis of students' participation patterns in whole class discussions and their narratives about experiences in these discussions. The findings show that all students enact agency in discussion, but differences lie in the extent to which students perceive that they can enact agency. We find that social structures that help to create and perpetuate differences in students' sense that they can enact their agency. We discuss the implications of these findings on what teachers can do to support equitable participation in talk in the service of equitable opportunities for learning.
\end{abstract}

Keywords:

Agency • Engagement • Dialogic Instruction • Classroom Dialogue • Accountable Talk • Science Education

Sherice N. Clarke

University of Pittsburgh

Learning Research \& Development Center

3939 O'Hara Street

Pittsburgh, PA 15260, USA

sclarke@pitt.edu

Tel: +1-412-624-7487 


\section{Introduction}

Students bring a wealth of knowledge and resources with them into science classrooms. These faculties serve as a foundation for knowledge construction (Chi \& Roscoe, 2002) and important resources for sensemaking about scientific concepts (Berland \& Reiser, 2009; Chin, Brown \& Bruce, 2002; Chin \& Osborne, 2010). When students make use of these resources in the context of collaborative argumentation discussions, they have opportunities to externalize their emergent understandings, consider alternatives, recognize misconceptions, and potentially transform them in light of new evidence or ideas. When carefully guided by teachers, this shared reasoning process through talk has the potential to "grow the mind", in addition to students' learning of scientific concepts (Resnick et al, 2015b).

There has been growing interest in dialogue as a means through which to support student engagement in the practices of science as they learn scientific concepts (Osborne, 2010; NRC, 2012). A proliferation of studies on talk and learning across school subjects has shown that when teachers carefully guide students in the shared process of sensemaking about domain concepts, students benefit in terms of steep increases in learning, including long-term retention, domain transfer and reasoning development (Clarke, Resnick, \& Rosé, 2015; Littleton \& Howe, 2010; Resnick, Asterhan, \& Clarke, 2015a). We refer to this particular kind of teacher-lead discussion as dialogic class discussions.

Examining discussion in terms of aggregate discourse processes and outcomes highlights that the dialogic classroom is one where there is a density of productive interactions between students. However, several studies have begun to examine the nature of individual student engagement these kinds of discussions. These efforts have helped to show that there are significant differences in the ways in which individual students participate in class discussions, which have implications for individual learning (Black, 2009; Clarke, 2015; Kelly, 2007). Thus, while one of the goals of dialogic discussions may be to engage students in intermental thinking processes to support the development of intramental processes, some questions are raised when we consider that discussions of this kind may not necessarily yield equitable participation across speakers (Clarke, 2015).

Students do not enter classrooms with an absence of the ability to engage in reasoning through talk (Howe \& McWilliam, 2001). However, they may differ in the soundness arguments, as a well as the structural and discursive norms of reasoned argumentation (Chin \& Osborne, 2010; Sandoval \& Millwood, 2005). Appropriating these standards, however, is developmental and can be augmented through instruction (Felton \& Kuhn, 2003; Herrenkohl \& Guerra, 1998; Adamson, Dyke, Jang, \& Rosé, 2014; Mercer, Dawes, Wegerif \& Sams, 2004). Analyzing students' narratives about participating in dialogic science discussion, Clarke (2015) showed how students perceived the whole class discussions as a distressing space, insofar as not all students were willing to enter discussions where they made their emergent thinking public. Several studies help to highlight the ways in which social structures imbue some linguistic forms and lived experiences with more or less legitimacy in the classroom, and shape student opportunities for engagement as a consequence (e.g., Zohar, 2004; Nasir \& Hand, 2008; 
Gee, 1985). In this sense, student participation in dialogic class discussions is not simply an externalizing of cognitive processes, but also comprised of the dynamic interplay between interlocutors in dialogue, the social context in which learning dialogues are situated, and the institutions and histories that structure these relationships. This dynamic interplay between interlocutors, institutions and histories can have the effect of shaping the opportunity space for student participation in dialogue.

In this paper, we extend such research by focusing on a particular aspect of engagement in science discussions: the nature of students' agency to participate in these discussions. We consider two primary questions with respect to students' agency in dialogic science discussions. First, what is the nature of students' sense of agency to participate in discussions? Second, what is the nature of students' enacted agency to participate in discussions? We answer these questions through the analysis of classroom discussions and student narratives about participating in these discussions. This study is situated within a longitudinal study on teacher professional development on a certain form of dialogic pedagogy in science, Accountable Talk (Clarke et al, 2013). This work was situated within an urban school district in the U.S.. Thus we examine student agency in the context of class discussions that were in the process of evolving discursively from predominantly recitation (e.g., I-R-E (Mehan, 1979), towards dialogic pedagogy (Resnick et al, 2015a). Our goal is to better understand what it means for students to be persistantely on the margins of this kind of learning dialogue and to understand how more equitable student engagement could be supported in spite of the social structures that shape participation.

\section{Conceptual Framework}

\subsection{Why Talk and Participation Matter in Discussion}

Does simply 'being there', in a context where rich collaborative sensemaking through discussion is occurring, an adequate enough condition to produce learning? Or, are more "active" forms of participation in dialogue needed? Prior research suggests that there is a minimum threshold level of engagement needed in order to benefit from discussion in terms of learning (e.g., Chi, 2009).

On the low end of the engagement threshold, that is to say the minimul level of engagement in discussion needed for learning to occur, several studies have found that students need to verbally engage with one another's ideas, e.g. negotiation for meaning through asking questions. King, Rosenshine and colleagues examined the degree to which students asked each other questions during collaborative learning and the quality of those questions in relation to learning outcomes (King, 1992, 1999; King \& Rosenshine, 1993; Rosenshine, Meister, \& Chapman, 1996). They found that when students ask each other questions during collaboration, groups were more effective at problem solving and individual learning outcomes increased (King, 1999; Rosenshine, et al., 1996).

On the high end of the engagement threshold are forms of engagement in discussion that are more active in nature with respect to both interlocutors and ideas, and tend to yield 
robust learning outcomes. In particular, several studies of small group and dyadic problem solving have examined particular discursive interactions that seem to yield robust outcomes (e.g., explanations, transactive reasoning and disagreements) (Asterhan \& Schwarz, 2007; Asterhan \& Schwarz, 2009; Azmitia \& Montgomery, 1993; Kruger, 1992; Teasley, 1997).

First, explanations are utterances (or a sequence of utterances) that function to externalize an individual's knowledge or understanding of domain concepts. In conversational interaction, an explanation becomes an ideational artifact/object for interlocutors to make sense of in relation to their problem solving goals. Research has shown that when students engage in explanation during collaborative problem solving discussions with peers, their knowledge, conceptual understanding and success in problem solving increases (Asterhan \& Schwarz, 2007; Asterhan \& Schwarz, 2009). Explanations have also been shown to support the development of deep shifts in conceptual understanding. Second, transactive reasoning, talk in which the reasoning of discussions (self and other) is 'interpenetrated', has been shown to support both collaborative problem solving, as well as growth in reasoning abilities (Azmitia \& Montgomery, 1993; Berkowitz \& Gibbs, 1983; Kruger, 1992; Teasley, 1997). Third, disagreements, which include close cousins like challenges to ideas and contradictions, have been shown to not only support learning gains and conceptual change, but have also support long-term retention of learning (Howe, 2010; Kruger, 1993; Mugny \& Doise, 1978).

Collectively, studies on this kind of discursive interaction show that it is not simply the incidence of these interactions that produce benefits for learning. Rather, it is the students who use these moves during discussions that seem to benefit most in terms of learning. Studies of explanation have found that it is the explainers who have the greatest growth in conceptual understanding, when compared to listeners to those explanations (Fuchs et al., 1997; Howe et al., 2007; King, 1992; King \& Rosenshine, 1993; Slavin, 1987; Veenman, Denessen, van den Akker, \& van der Rijt, 2005; Webb, 1991; Webb et al., 2009). However, several studies have documented that it is possible for listeners to make similar gains as speakers. Webb and colleagues found that when listeners make immediate use of explanations to solve novel problems (in the context of mathematics instruction) they show more robust learning gains akin to those of explainers (Webb \& Mastergeorge, 2003; Webb, Troper, \& Fall, 1995). Similarly, Asterhan \& Schwarz have found that if a recipient of an explanation actively externalizes their understanding of that explanation, these listeners can also undergo conceptual change. Similarly, with respect to transactive reasoning, Kruger found that it is necessary for students to engage with their peers' reasoning in order to positively impact group performance. If a student excessively self-transacts to the extent that they are essentially monologizing in dialogue, dyadic or group performance suffers (Kruger, 1992).

Together, these studies highlight that certain forms of verbal engagement (e.g., explaining to peers, engaging with one's own and peers' reasoning, and responding to peers' challenges to ideas) tend to yield greater increases in knowledge, conceptual understanding, and reasoning. Collectively, this evidence suggests that silence may not necessarily be a productive form of engagement in dialogue, unless one is cognitively 
engaged in discussion albeit silently. Listening can be productive for learning if students make use of the ideational artifacts put forth by their peers.

\subsection{Inequitable Participation in Dialogic Class Discussions}

A series of studies have shown stark differences in verbal engagement in dialogic class discussions (Black, 2009; Clarke, 2015; Kelly, 2007, 2008). Clarke (2015) conducted a linguistic ethnography of dialogic instruction in science in a low-performing urban high school that serves African-American students. Examining student participation in dialogic class discussions in one class over six consecutive weeks, Clarke found that $50 \%$ of students almost never spoke during the six weeks of discussion-based instruction. In addition, when the distribution of all student utterances was examined, it was found that four students in the class dominated the conversational space for the entire six weeks. Black (2009) observed a similar pattern in the context of primary grade 5 mathematics classrooms over a five-month period of observation. In a large-scale, multi-school, multiclass, and multi-year study of verbal engagement in dialogic class discussions in literacy, Kelly reports stark patterns in engagement in class discussion by race and socioeconomic background (Kelly, 2008). Analyzing a corpus data that included 117 classrooms, 2,051 students, and a total of 17,351 student conversational turns, he reports that students from high socio-economic backgrounds engage more frequently than students from lower socio-economic backgrounds. Kelly also found that students who had lower achievement on pre-tests were less likely to engage in discussions than students with higher achievement. Moreover, on a whole, less verbal exchanges were observed in classrooms that served primarily African-American students.

The aforementioned findings cast a shadow on dialogic instruction, as they highlight that not all students participate in dialogic discussions, and simply 'being there' in the context where rich collaborative sense-making is occurring, is not necessarily an adequate condition for all to benefit in terms of learning. Findings of this kind raise the question of whether these are stable patterns, and to what extent, given the structures that shape student engagement, is it possible for students themselves, and/or teachers, to be agents of change to shift these patterns?

\subsection{Hybridizing Agency}

Agency is one of the most ubiquitous constructs in the educational sciences, yet surprisingly ill defined. It is often described as an outcome of the educational process, however it is very rarely systemically examined in educational research (with a few exceptions e.g., Rainio, 2008; Barton \& Tan, 2010). This special issue helps to fill this gap in educational inquiry. Yet still, defining agency is somewhat problematic given the various intellectual ties the construct has with different disciplines. Agency counts as both a central question of sociological thought, and a legitimate and empirically validated psychological construct used in social and cognitive psychology. While these disciplinary perspectives share a central notion of an agent and action, the locus of agentive action differs in these respective research traditions. The sociological lens conceptualizes agency as a function of social structures within which individuals are embedded, whereas, psychological traditions conceptualize agency as a self-regulatory capacity of an 
individual. However, we believe that both traditions offer a bit of grist for examining educational processes, which are uniquely constituted by both social and cognitive processes.

We take the view that a hybrid model of agency is not only needed, but well suited to the study of learning processes through dialogue, given the dual nature of this type of learning i.e., cognitive processes that are shaped in and through social interaction, which are situated within a particular social context (Cauce \& Gordon, 2012). For the purposes of this investigation, we bring together two particular formulations of agency to examine student agency in classroom dialogue. Firstly, a formulation that conceptualizes the relationship between conceptions of self and one's intention to take action (Bandura, 1989), and the second, a formulation that helps to conceptualize the relationship between the action and social structures that create affordances for one to take action (Giddens, 1984). At first glance, these perspectives might not seem likely bedfellows - Bandura himself argues that social cognitive theory rejects the notion of duality of structure and agency (2006), a notion that is central to Giddens' formulation (1989). However, with respect to the present investigation, we believe that a hybrid model of agency affords a special kind of bi-focal lens for examining learning that is shaped in social interaction (Vygotsky 1978) and situated within social systems, i.e., with teachers and students, in classrooms, schools and cultures.

Here we define a hybrid model of agency as both the intention (Bandura, 2006) and capability (Giddens, 1984) to take action in the world to change the course of events. Intentionality highlights the self-regulatory nature of agency, "the exercise of selfinfluence in the service of selected goals and desired outcomes" (Bandura, 2006, p. 165), e.g., how a student might make particular moves in the context of class discussion to advance theirs or their peer's learning. Capability, however, refers to the social structures that create opportunities for an individual to take action, e.g., institutional structures that govern classroom interaction like whether a teacher allows for student-generated questions to be asked in the course of learning. Taken together, they help to frame the notion of student agency that we adopt: the intention and capability to take action with respect to one's learning in learning activities, in order to change the trajectory of theirs and their peers' learning.

There are several important features of a hybrid model of agency that need to be delineated for our analyses: the nature of the agent, action, and the locus of agency. An agent is an individual that takes action to influence or change of the course of their circumstance. Giddens highlights that an individual can only be classified as an agent if they possess the power to take action towards making a difference. Thus it is possible to lack agency on account that an individual does not possess the power to make an action of significance (Giddens, 1984, 14). In addition, an individual may not believe that they can make take action of any significance, thus may lack the 'incentive' to take action, regardless of however faulty this self-appraisal might actually be (Bandura, 1982; 1997; 2006). However, believing they one could be efficacious in reaching a desired outcome, has been shown to be associated with the intention to take action (Bandura, 1982). To summarize, a hybrid model of agency is one that conceptualizes dual forces of influence on agency: social structures and self-appraisals. 
However, we appropriate Giddens' theory of structuration in this work, which argues that social systems and social structures are a framework for activity. This framework is not fixed -- rather it is malleable, and it is the agency of individuals within these systems that can recursively shape structures, activities and norms, thus either reproducing practices and relationships between actors or reshaping them. In other words, the nature of human agency enables the possibility for structures to be reshaped over time. Both Giddens and Bandura conceptualize the individual as embedded in a constant flow of activity, in which actions could be taken. These activities serve as data points for an individual to examine the relationship between actions and their consequences. It is this causal relationship, if noticed, that leads to a recognition of one's possible influence on activities, and a recognition of oneself as an agent, and therefore the locus of agency (Bandura, 2006). In other words, it is this reflexive process through which agency can develop (Giddens, 1984).

We appropriate these distinctions to develop a working definition of student agency for the purposes of our analysis of student agency in dialogic science discussions. We suggest that a student can be an agent if they have the intention and power to take action in learning activities, to change the trajectory of their learning. Thus, not all of the activities that one engages in during learning are necessarily agentive. Rather, it is the actions that are intentional and can make an influence on learning trajectories that can be considered agentive with respect to learning.

\section{Method}

\subsection{Setting}

The present study is situated within a longitudinal teacher-level intervention on Accountable Talk. Accountable Talk is a class of dialogic pedagogy structured around specific talk moves that teachers can use to facilitate academically productive discussions. The goal of the longitudinal intervention was to embed this form of academically rigorous instruction in an urban high school that served students of the greatest need. Details of the teacher-level intervention are reported elsewhere (Clarke et al., 2013). The study was conducted in an urban high school, Callen High School ${ }^{1}$, which serves a population of students with significant low achievement and attainment, especially in science ${ }^{2}$. Teachers were embedding Accountable Talk into biology

${ }^{1}$ Callen High School is a pseudonym for the in Western Pennsylvanian high school in which this study was conducted.

2 Callen High School serves a population of students that is 35\% African-American, 44\% White, $13 \%$ Asian and 3\% Hispanic, with $77 \%$ of the student body receiving free/reduced lunch, an index for SES. 3.9\% of African-American students from the 2011-2012 academic school year achieved a score of proficient on the State standardized biology exam, and $25.6 \%$ of White students. In addition, 29.4\% African-American students achieved a score of proficient on the State standardized mathematics exam, and $43.8 \%$ achieved a score of proficient on the literature exam. While, $60 \%$ of White students achieved scores of proficient in mathematics, and $74 \%$ proficient in literature. 
instruction for the first time to foster collaborative student reasoning and thinking in biology. The classes of a teacher (Mr. Stanley), who was a participant in the longitudinal teacher-level study, served as the context for this study.

\subsection{Data Sources}

Mr. Stanley's whole class discussions in biology were observed from September 2011 through May of 2012. A total of 44 observations were recorded and transcribed of $\mathrm{Mr}$. Stanley's three sections of $9^{\text {th }}$ grade biology. A subset of 16 consenting students ${ }^{3}$ in $\mathrm{Mr}$. Stanley's classes were interviewed at two time points, one several weeks before a small group discussion activity, and the other several weeks after it (group discussion activity reported on in Adamson et al, 2014).

Mr. Stanley's Accountable Talk discussions in biology were observed several times throughout the school year. The data collection protocol for observations involved audio recording classroom talk. In addition, we used bespoke computer software to live transcribe the discussions, attributing conversational turns to speakers (Adamson, LWT). Audio and live-transcriptions were synchronized, and fully transcribed. The corpus consisted of 44 transcripts.

The student interview protocol was an adapted version of McAdams' (2008) narrative interview. Interviews were audio recorded and transcribed. The interview was designed to elicit students' experiences in Accountable Talk discussions in their biology class. The protocol probed students to identify salient moments in class discussions thematically and explicate those moments in a narrative form (e.g., high points, low points, turning points, challenging points, wisdom events, and moments of regret).

For each salient moment that the student interviewee identified, the interviewer asked the student to explicate the moment by telling a narrative that included what happened, who was involved, when it happened, what their opinion of the event was, why they felt it was salient, and if anything, what happened after the event. The ways in which people tell stories can provide insight into how they understand their experiences. Thus, a narrative is not necessarily the 'truth' of an event, but rather, an account that is an interpretation of an event. And often, that interpretation is made through the lenses of the present (Ricoeur, 1980). These features of narrative can be subjected to analysis, and as a result, can provide a means through which to examine the ways that people understand their experiences.

\subsection{Analysis}

Given that our hybrid model of agency is one that conceptualizes students' self-appraisals and social structures as dual influences on agency and action, in our analytical approach, we draw on Rainio's distinction between sense of agency and enacted agency (Rainio,

\footnotetext{
${ }^{3}$ Parental consent was obtained for all students who were interviewed and who's participation in discussion was tracked using LWT for this study. All names have been replaced with pseudonyms.
} 
2008). We use the notion of students' sense of agency, to examine students' narratives for the ways in which they expressed students' self-appraisals, intentions to act, and social structures that shaped those intentions. We use the notion of enacted agency to examine students' participation in dialogic discussions in science. In this sense, we examine class discussions for evidence of students' exercise of agency to participate, and social structures that may afford those actions.

We make use of several forms of discourse analysis to analyze observation and interview data. We used conversation analysis on the observational data to examine turn-taking patterns (Hutchby \& Wooffitt, 2008). Turn-taking refers to ways in which speakers take turns in conversation, e.g. teacher asks question, followed a student's response to that question. As previously discussed, not all activities made by actors are necessarily enactments of agency. In seeking an analytical approach to examining students' enactment of agency in classroom dialogue, we examined particular turn-taking patterns. We suggest that is possible to make a distinction between agentive and less-agentive actions in classroom discussions by examining precisely what gives rise to a students' conversational turn.

We conceptualize unsolicited turns in classroom dialogue as an indicator of enacted agency. Unsolicited turns are conversational turns where the interlocutor makes the choice to engage in discussion. We coded the data for two kinds of unsolicited turns: unsolicited questions and unsolicited responses. Unsolicited questions are questions that a student asks without being prompted to do so. Likewise, unsolicited responses are responses to previous utterances that were not solicited by the teacher or another student. Again, the student had the choice to ask a question or respond.

We conceptualize solicited turns in classroom dialogue as non-agentive actions. Solicited turns are those where the teacher expressly elicits participation. We conceptualize these kinds of turns as less agentive because in these interactions, the student is given less choice to contribute, given the social norms of classrooms where the teacher's authority is often used to determine who gets to speak. We coded the data for solicited questions and solicited responses ${ }^{4}$. In order to distinguish between unsolicited turns and solicited ones, coding looked for linguistic markers that indicated the impetus of the turn.

We used narrative analysis to examine the interview data for students' sense of agency. Riessman defines narrative simply as "talk organized around consequential events" $(1993,3)$. Labov and Waletzky suggest that there are two primary functions of narratives: (1) referential, that is, referring to past experiences; and (2) evaluative, insofar as narrators interpret their experiences $(1967,13)$. The evaluative function of narratives suggests an internal coherence to the stories that people tell, and an internal logic. We examined the reasoning structures in their stories about salient moments in discussions in order to gain insight into the participation patterns we observed in the class discussions.

\section{Findings}

\footnotetext{
${ }^{4}$ We found the latter distinction not particularly meaningful as solicited questions rarely occurred
} 


\subsection{Students' enacted agency in dialogic discussions}

We examined students' solicited and unsolicited turn-taking patterns in discussion, by case (student) and by lesson sequentially. This analysis revealed several patterns of students' enacted agency in class discussions.

First, we found that some students participate in discussions frequently, and some only rarely, a finding consistent with previous studies in urban schools (e.g., Clarke, 2015). Seven of the 16 students participated in discussions above average, where the average number of contributions across the sample was 80 turns (hereafter referred to as high contributors). High contributors' ranged from 119-274 turns across the dataset. The remaining nine students participated well below average (hereafter referred to as low contributors). Low contributors ranged from 11-41 in total turns over 14-15 observations of their respective classes.

Second, examining when we examined what gave rise to students' contributions, teacher solicited or unsolicited, we found the pattern was overall consistent with students' participation profiles. High contributors have a correspondingly high number of unsolicited contributions, which we interpret has a high degree of enacted agency. Low contributors, have a correspondingly low number of unsolicited turns relative to high contributors. However, on average low contributors make more unsolicited contributions than the teacher solicits from them, (with the exception of Kristina and Joseph (Figure 1)). Thus, we interpret this as evidence that low contributors have agency to participate in dialogic discussions in science, but appear to exercise this agency more sparingly relative to high contributors. We interrogate this finding further shortly when we discuss the selfreport data.

\section{[INSERT FIGURE 1 ABOUT HERE]}

Third, Figure 1 helps to highlight that Mr. Stanley solicited more contributions from high contributors than from low contributors. Moreover, Mr. Stanley made very few solicitations of extremely low contributors. For example, Deshaun, a student with a total 20 turns across the series, was asked to contribute six times across lessons, despite having been in attendance for 13 of the 14 observed lessons. In other words, students that enact agency more readily are students that Mr. Stanley seems to more readily defer to for contributions in discussions.

Finally, examining the turn-taking patterns, within each student case, we found local pattern within lessons that we refer to as an echo effect (Excerpt 1). By echo effect, we are characterizing a participation pattern within lessons and student cases whereby the teacher's request for a contribution from a particular student is followed by an unsolicited contribution from that student later in that lesson. This is a pattern that was first observed across lessons in low contributor cases, and then confirmed across the dataset, as it was also present in high contributor cases. In addition, we found that the echo effect was bidirectional in most of the student cases. Most cases (students) included both instances where Mr. Stanley's request of a contribution was followed by that student's unsolicited contribution later in the lesson, as well as lessons where an unsolicited contribution of a 
particular student was followed by Mr. Stanley's request for a contribution from them later in that lesson (e.g., Excerpt 1).

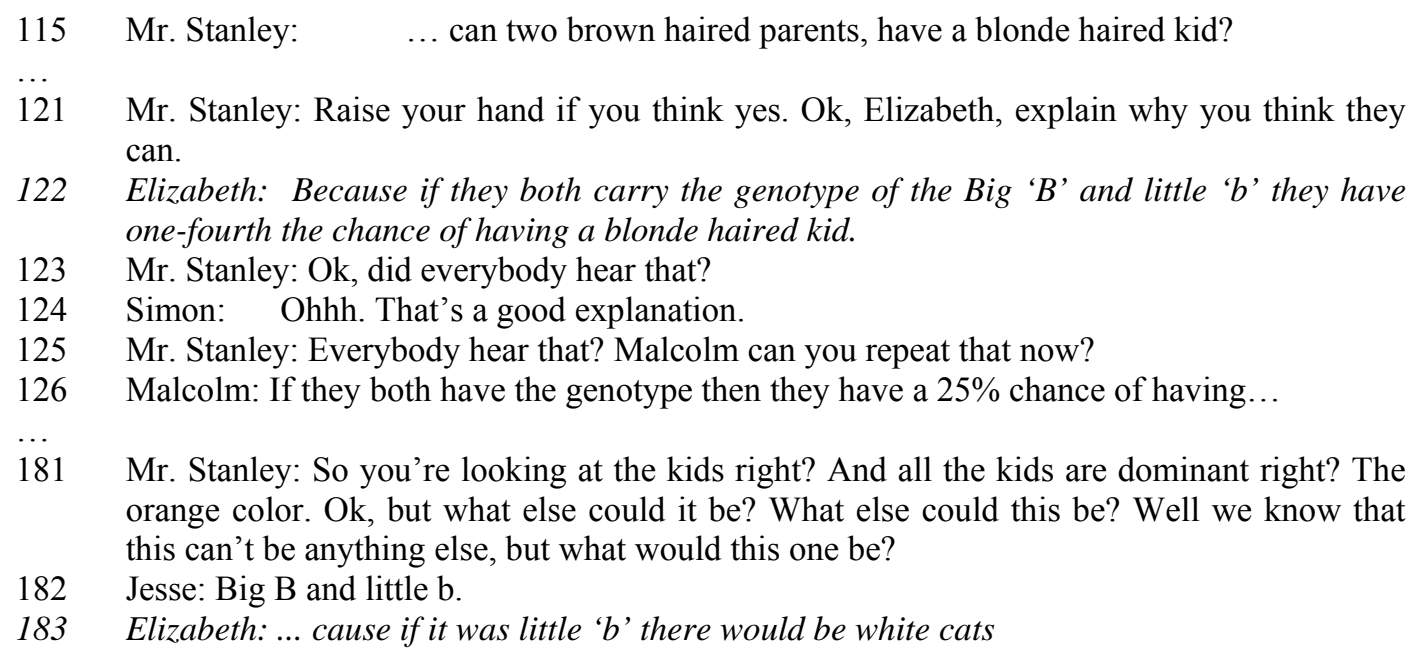

Excerpt 1. Teacher Initiated Echo Effect in discussion.

In Excerpt 1, we see the teacher (Mr. Stanley) solicits an explanation of Mendelian inheritance from Elizabeth in a Punnett Square discussion (line 121). Elizabeth provides an explanation in line (122), which is her first verbal appearance in this lesson. In the turns that follow her explanation, Mr. Stanley marks her utterance for the class, by not only checking that the other students have heard it, but that they are able to reformulate it, which Malcolm does in Line 126. The discussion carries on for about 60 additional conversational turns, then we see Elizabeth re-enter the discussion in line 183, unsolicited. We classify Line 183 as an instance of an echo effect, whereby the teacher's request of Elizabeth's contribution is followed by Elizabeth's subsequent enactment of her agency to participate.

\subsection{Students’ Sense of Agency in Dialogic Discussions}

In order to examine students' sense of agency in these discussions, we analyzed the ways in which students told narratives about their experiences in discussions. We reduced the dataset to narratives that either explicated an action take in discussion, or inaction (e.g., answers questions, deciding to be silent). We then inductively coded the data further to characterize the intentions students articulated as underlying the actions they took, with only a few without an underlying intention imbedded within the narrative. In narratives where students explicated an action they took discussion, and their intention expressed a sense of volition for taking that action, we coded as sense of agency (e.g., Excerpts 2, 3, $5,6)$. Narratives were students described actions or inaction in discussion, but expressed a lack of control in taking action, we coded as no sense of agency (e.g., Excerpts 4, 7).

\section{[INSERT FIGURE 2 ABOUT HERE]}

Figure 2 shows that low contributors conveyed more narratives than high contributors in which they expressed lack of a sense of agency to take action of consequence in class 
discussions. The incidence of this kind of narrative might mean that experiences in which students felt a lack of a sense of agency may be more salient to students that rarely contribute, than those that often do so.

When we examine these narratives more closely at the level of intentions that students articulated for actions in discussion, we find that narratives of these respective student populations differ in some important ways. What low contributors' narratives share in common is that they emphasize the role of that social structures have on sense of agency (e.g., Excerpts 2, 3, 4). While high contributors, comparatively, express a sense of agency that is driven by a desire to understand the science content (e.g., Excerpts 5, 6, 7).

Well, I think when we were talkin' about, well Mr. Stanley was talkin' about cellular respiration. He was asking us questions- well, questions about it and then like, a whole bunch of people didn't know the answer. And then they were just sittin' there it was all silent and I just answered it. And then people thought it was wrong, and then I actually proved I was right then everybody started getting mad, and then some people shout I think and then Mr. Stanley showed them I was right and it was the same way I showed them, but they didn't believe me. So he had to show them again. Then they did like, something- there was something else. It was- I don't even remember. That was a long time ago. But he was asking questions and nobody knew the answer to it. But I got it right.

Excerpt 2. Deshaun's sense of agency (low contributor)

In Excerpt 2, Deshaun tells a narrative about a moment where he had a sense of agency to answer a question that Mr. Stanley posed to the class, and enacted that agency. There is internal coherence that runs through the segments of Deshaun's narrative that helps us to interpret why Deshaun tells this particular narrative, and what sense he makes of this moment. Excerpt 2 is structured around the notion of "the right and wrong answer". The way in which he narrates this story highlights throughout, who was right (him), who was wrong (his peers), who believed he was right (himself, Mr. Stanley), who believed he was wrong (his peers), who had the authority to confirm that he was right (Mr. Stanley), and ultimately, he concludes with a coda that reiterates the meaning he seems to attach to this particular moment "he was asking questions and nobody knew the answer to it. But I got it right." These structural features of his narrative help to create an internal coherence across the clauses, like a framework. We use these narrative markers to infer that the intention of Deshaun's action was ultimately to "get it right". What is important to highlight, is how Deshaun's story is punctuated by social others that serve as principle actors that drive the action in his story (peers, Mr. Stanley, and one could argue, the standards of knowledge in this aspect of biology). In this sense, 'getting it right' is relational.

[Researcher: Does any point stick out to you as a turning point?...] ...Probably like personally whenever I like really understood. 'Cause like sometimes in class I'll like pretend I understand. [Researcher: $M m h m m$, why?] And-I don't know just like I'm kind of like a quiet person and I really don't like to be all out there and everyone know I', having difficulties in class or whatever. But um, 'cause like I 
actually understood the Punnett squares and everything. That was like a plus for me. [Researcher: So you what actually happened in that moment?] Well, I don't know this one girl at my table she asked me um what one of the problems was like if I could help her. And I did help her and it ended up being right so that was a plus.

Excerpt 3. Kim's sense of agency (low contributor)

We see a similar structure in Kim's narrative about helping a peer. The way Kim tells the story, she sets up the contrast between this event and how she normally behaves in discussion. She oscillates in her telling between these respective time points, when she helped a peer (specific event) and pretending not to understand (her general practice). She develops the specific story by iteratively interrupted it with evaluation clauses that are temporally about her general practice in discussions. These evaluation clauses all begin with the conjunct "because" ("cause), which suggests a connection she is drawing between the specific event and her general performance avoidance practices. Intensifiers like "actually" further suggest the contrast she's drawing between the specific and the general, and in doing so provide insight into how this event may have been particularly salient: because she noticed she was able to provide help for her peer and that help was correct. Relationally, Kim's narrative highlights how her sense of agency seems to be mediated by others, in particular her desire to not show others when she does not understand. She punctuates this story with the coda "it ended up being right so that was a plus", which like Deshaun, suggests that validation from teacher in the form of the teacher marking her correctness, is particularly salient to her.

My greatest challenge is getting my word out 'cause sometimes I'm a little bit shy and I don't like talking 'cause I don't want to be wrong. But yeah. It's definitely getting my word out, 'cause I don't know if it's right or wrong and I'm just like- I don't want to make a fool of myself saying I'm completely wrong and uh, I don't want to be a show off if I'm saying something too like, smart so that's what's challenged me. Saying stuff.

Excerpt 4. Saul's lack of a sense of agency (low contributor)

Saul, another low contributor, shares a narrative which expresses his sense of a lack of agency to 'get his word out', which is not dissimilar from the narratives that Kim and Deshaun tell. Like Kim's telling, Saul's narrative sprinkles his evaluations throughout with evaluation clauses that give insight into how he interprets parts of his story, e.g., I don't like talking because I don't want to be wrong. In this narrative, his inaction is organized around a kind of invisible other, that is never directly stated 'teacher' or 'peers' but in every way implied in the way in which narrates this story. In Saul's narrative, these are the spectators to his making "a fool of" himself, and being a "show off". In this sense, these deictic expressions imply a general spectator who would be privy to his actions and to evaluate them as such. Given the age group of this cohort of students, it possible to infer that his peers are the spectator.

Contrastingly, high contributors' narratives differ in that the intentions those students refer to, seem to be driven by a desire to understand. We differentiate a desire to understand from expressions from low contributors' "getting it right", as the former 
appears to be mediated by something internal and for its own sake, rather than the latter, which points to external mediators (e.g., teacher, peers, domain standards) (Excerpt 5).

[Researcher: What sticks out as high point in discussion?] I think for me it was cause I was tryin' to figure out like the way the little Punnett square went it was, it was like big R little $r$, big R little $r$ or somethin' but like the way I put it together was still, like I was tryin' to figure out if that like the outside gene would possibly overcome the recessive gene. Recessive means it like has to happen. [Researcher: No dominant is it has to happen, I think.] Oh, yeah dominant, dominant means it happens, but I was tryin' to figure out cause there's still that $1 / 25$ percent chance that the recessive gene is still gonna come out, so I just thought that the recessive gene could over turn the dominant gene, but he said that I was workin' too far ahead and I was like to ahead, But I thought that was interesting, just for the simple fact that like just the way I think about things more. I try to like look at all different types of like it but he just said that it does happen every once in a while, but not occasionally.

Excerpt 5. Wendy sense of agency (high contributor)

First, what is particularly noteworthy about Wendy's narrative is that when she is asked what was a high point in discussion, she begins by describing what she was trying to understand in that discussion. Moreover, there is almost no reference to any other person in her narrative except when she says "he said that I was working too far ahead", and "he just said" which given that teachers often monitor the pace of learning content, we interpret that "he" as referring to Mr. Stanley. Thus, in Wendy's narrative, she expresses a sense of agency with an intention to "try and figure out", and appears to enact that agency until the teacher says that she's too far ahead of the where the class was conceptually.

[Researcher: a moment in the discussion where you felt like, wow, I really know this?] Well after say I was doin' a Punnett square and I found out like all the capitals and lower case I'd be like wow, I can't believe I just figured out that there's a possibility of my son having brown hair or my son having blond hair. So really the percentages again... And then like we took a minute so everyone could catch up an all that and they we went back into a discussion about the percentages. At that point in the discussion I um practically just said that I like how we figured this out and it was good because a lot of people were engaged a lot of people were trying to figure out what color hair their son or daughter would have. Just more people were interested in it.

Excerpt 6. Derick's sense of agency (high contributor)

Similarly, Derick (Excerpt 6) expresses his sense of agency to share his solution in a discussion of genetic inheritance. Like Wendy, his narrative is organized around the genetics concepts that he was grappling with. Whereas we find in the narratives of low contributors', when asked about moments where they felt knowledgeable, students primarily told narratives about moments where they 'knew the answer' or 'got the answer right'. Again, we argue that that is a qualitatively different driver for action than 'seeking understanding'. The role of 'the other' is not absent in the narratives of high contributors, but in general they seem to play a more constructive role in these narratives e.g., seeing other students as resources for fostering their understanding, and seeing themselves as a resource for other students' learning, seeing others actions as an indicator of collective motivation (e.g., Excerpt 6). 
As figure 2 helps to highlight, there were very few narratives in which high contributors expressed lack of a sense of agency (e.g., Excerpt 7).

Well, sometimes I just don't get stuff and then it starts to bore me and I don't get it. I just don't pay attention.

Excerpt 7. Ben's lack of sense of agency (high contributor)

In excerpt 7, Ben conveys inaction with respect to learning "I just don't pay attention." The way in which he narrates this has a sense of directionality - one thing leads to the next thing, and then to the next, and so on, e.g., when he does not understand, and then he gets bored and then he does not pay attention. Again, we can see that in this high contributor narrative, this story of inaction is organized around Ben, and what happens when he does not understand. Moreover, he does not refer to others or social structures having an impact on the directionality of tuning out. Rather, this is a story that is driven by Ben and his understanding.

\subsection{Elizabeth's Case: the emergence of a sense of agency in science discussions}

Thus far, we have characterized the overall pattern of the data across high and low contributor cases. We return to Elizabeth's case (Excerpt 1), in order to examine in greater detail the relationship between students' sense of agency and enacted agency. We focus on Elizabeth, in particular, as one of the goals of this study was to understand how students negotiate access into discussions from the margins. Figure 1 shows that Elizabeth was a low contributor in the discussions, both because she was rarely called on, and because she did not often participate on her own volition. When we examine Elizabeth's participation at the lesson level, we find that her participation pattern oscillates from no contributions (four lessons) to up to five utterances in a lesson ( 8 lessons).

Elizabeth defines herself as "more of a listener," which not incompatible with her observed participation patterns in the 12 lessons (Figure 1).

I felt really not smart when he started talking about something and he [Mr. Stanley] called on me and I didn't really know what to answer. But I think it's that I didn't feel like- it didn't feel good not to know something, but it's pretty bad. I told him that I didn't really know much about the topic so I couldn't really say anything to it. [Researcher: And then what happened?] - and he just moved on to another person. They were able to answer the question and I wrote it down, so likefor later reference I could just go back and look. [Researcher: ok. why do you think that sticks out to you as a low point?] ... Because I didn't have like, the intelligence- not intelligence- the answer- no, knowing what the answer was. And I don't like not knowing things.

Excerpt 8: Elizabeth, Interview 1: "I didn't have like, the intelligence"

In Excerpt 8, Elizabeth describes a moment in class discussion in which she is called on. She did not know the answer to the teacher's question, so the teacher called on someone else to answer. What is important to highlight about this narrative, is Elizabeth's evaluation of this moment, "because I didn't have like, the intelligence- not intelligencethe answer- no, knowing what the answer was." One could argue that her evaluation lies 
in the last clause of that segment. However, her hesitation and recasting seems to suggest that she may be generalizing, equating a moment of not knowing the answer with having intelligence. We interpret this narrative as one that expresses a low sense of agency because she felt she expresses both that she did not take action as well as a sense that she could not have participated, on account that "really couldn't say anything." What is also important to highlight is the negative impact inaction seems to have for her, i.e., "it didn't feel good" and that "it's pretty bad," and later, "I didn't have like, the intelligence."

However, a case like Elizabeth's raises an important question about the nature of student agency in dialogic discussions. Is students' sense of agency and enacted agency stable and dispositional, or is it emergent and able to be subjected to disruption? When we examine Elizabeth's narratives of unsolicited turn taking, a feature that we observed across cases becomes prominent, what Giddens (1984) and Bandura (2006) refers to as the reflexive nature of activity: noticing as the locus of agency (Excerpt 9).

Um, there was one a few weeks ago where we were talking about different diseases and I did like to throw into that because I've dealt with a lot of stuff like that. Like, with my family and everything. So I felt like I knew a lot- a lot about it. So it felt good to just get like- become smart for a day... Or for 42 minutes. [Researcher: ok, interesting. And how did the other students respond?] I guess some of just started writing down. Some were a bit shocked that I like, knew so much about it... they were a bit shocked that I could say so much.

Excerpt 9. Elizabeth, Interview 1, becoming "smart for a day"

In excerpt 9, Elizabeth narrates an experience in discussion in which she enacted her agency. Examining the way in which she narrates this experience, we see that she interprets being able to "throw into" the discussion as feeling "smart for a day... or 42 minutes" (i.e., the length of the class period). However, the weight of this event might lie in what she describes as having happened next. As previously mentioned, Giddens argues that activities serve as data points for individuals to examine the relationship between actions and their consequences. He argues that if individuals notice the causal relationship between actions and their consequences, then they recognize their possible influence on activities. Here, Elizabeth notices how her classmates were making use of her contribution (i.e., notetaking) and their reaction to her participation (i.e., surprise). In other words, Elizabeth notices that she became a resource for her peers in the discussion.

I was pretty excited to answer all the questions because I just got this random outburst of like, "Oh, my God. I know the answer. I'm gonna answer it now." It was really exciting. "Cause usually- usually, I'm just like, "I'll just write this down. I don't really don't need to raise my hand. I'm not much of a talker anyways." But it was a hard point because I was just so proud of myself for getting the courage to raise my hand.

Excerpt 10: Elizabeth, Interview 2 "getting the courage to raise my hand"

Because usually, if I don't know it I'll just keep writing and I just won't talk or just not even acknowledge the question, but definitely that I knew this stuff so I became like, this person who just likes talking now. Sometimes I don't shut up.

Excerpt 11. Elizabeth, Interview 2 "now I became... this person who likes talking now" 
Excerpts 10 and 11 provide further evidence of Elizabeth's reflexivity with respect to events in discussion. In Excerpt 10, she describes a moment in which she realized she could answer, and describes the excitement she felt in that moment of realization, and the pride she felt as a consequence for having the courage to participate. In Excerpt 11, she reports a dispositional shift, becoming a "person who just likes talking now," which she describes as a function of now knowing "stuff." Her solicited and unsolicited turn taking show some evidence of a perspectival shift (i.e., an increase in her turn-taking in the final observations), however since these data are cross sectional rather than consecutive observations, we cannot fully advance this claim.

Taken together, these narratives suggest the important role noticing can have for students on margins of discussion in particular, fostering their sense of agency to participate in discussion and their enacted agency as a consequence. Noticing that one could take action to advance one's on learning and that of others, and that that action results in positive outcomes may be particularly important for students that lack a sense of agency on entering discussions of this kind.

\section{Discussion and Conclusion}

In this paper, we sought to examine students' agency to participate in dialogic science discussions. We operationalized a hybrid model of agency to examine agency in dialogic class discussions. We proposed that a hybrid model of agency would enable the examination of agency in learning that is situated within a social system (the classroom), but entail cognitive processes that are shaped in and through social interaction. Our findings make several important contributions to understanding student engagement in dialogic science discussions. We discuss these in turn and consider the implications for what teachers might do to support the development of students' sense of agency, and enactment thereof to participate in the shared the reasoning process in science discussions.

The findings show that all students enacted agency to participate in discussion at some point during the study, as well as expressing a sense of agency to participate, regardless of whether they were high or low contributors. Thus, we conclude that all students in this study had agency to participate in these discussions. However, differences lie in the extent to which students perceived that they could enact their agency.

High contributors were far more frequent contributors without being explicitly asked to do so, but they were also the students that Mr. Stanley deferred to more readily for contributions in discussion. Mr. Stanley's solicitation pattern points to the way in which these micro-level interaction patterns can collect over time to build up more general participation patterns (i.e., high and low contributor distinctions), and within-class disparities of learning opportunities as a consequence. It is possible that Mr. Stanley defers to certain students (high contributors) because he knows they will have an answer that he's looking for, rather than students that seem less certain about their understanding and more reticent about engaging in general, as the narratives of low contributors suggest. However, this heuristic, if it can be called one, may over time have the effect of marking the kind of contributions that are valued, and who has the 'right to speak' in 
these discussion, which we see some evidence of in the narratives of low contributors (c.f., Clarke, 2015).

Students' sense of agency closely relates to the participation patterns we observed. High contributors almost entirely tell narratives in which they felt a sense of agency, while low contributors frequently tell narratives about moments where they perceived they lacked a sense of agency. In these narratives, low contributors emphasize the role of social structures and the positioning work that these students are doing in light of them. This might partially be related to the underlying positivist perspective of school science that advances the canonical view that science instruction is the dissemination of unquestioned truths (Driver, Newton, \& Osborne, 2000). While its not possible to know the kind of instruction students in the present investigation have had exposure to beyond the observed classes, their stance with respect to knowledge in discussions (i.e., right or wrong binary) suggests that students may bring to these discussions an implicit epistemological perspective about nature of scientific knowledge and how it is constructed. However, what is important to note of our findings is that this perspective is salient only in the case of low contributors.

What low contributors' narratives highlight is that taking action (or choosing not to) seems to be influenced by positioning work that these students are engaged in discussions, i.e., how they wish to be seen by others, and how they perceive they are seen by others (c.f., Goffman, 1959). The teacher's solicitation of participation from high contributors may also influence this difference, heightening the comparison for low contributors between themselves and high contributors. This would help to explain why the narratives of low contributors emphasized a sense of agency that was tethered to notion of 'being correct', whereas the narratives of high contributors expressed a sense of agency that emphasized what they were trying to learn of the science content. While there's no absence of the other actors in the narratives of high contributors, these narratives do no suggest that these students are engaged in the positioning work that low contributors are with respect to others. When high contributors' narratives indicate other actors, this relationship is framed as constructive rather than competitive.

Our hybrid model of agency helps to highlight that there are different influences on students' sense of agency, depending on the extent to which students enact agency to participate in discussions - and social structures seem to produce and maintain these differences. Further, these differences provide some insight into how sense of agency may change as students develop and enact their agency, shifting attention from positioning work to aspects of the learning itself.

In our hybrid model, we posited that conversational turns are data points that present students with opportunities to notice their actions and their consequences, thus noting the effect of enacting agency has and recognizing oneself as an agent as a consequence (Giddens, 1984; Bandura 2006). Thus we examined what students noticed about actions they took in discussion, and their consequences. Elizabeth's case, in particular, shows how her moments of action prompted the reflexive process about her contributions and they were taken up perceived by others. These moments of action in discussion may appear inconsequential to the naked eye when situated within the flow of a plurality of 
voices in class discussions, however, Elizabeth's narratives explicate how exceptionally consequential these moments were to her as an agent within these discussions. Thus, even just a few moments of action in the context of discussion can have a significant impact on sense of agency of low contributors. Coupled with the evidence on impact of active engagement in class discussions on students' learning (c.f., Resnick et al, 2015a; Clarke et al, 2015), our findings suggest that supporting students to actively participate in the discussion can both support their development of agency to participate, but also increase opportunities these students have for learning in these discussions.

The echo effect provides evidence how of the structures that create and maintain differences in agency, are also dynamic and allow for incremental development of agency. The echo effect highlights the proximal effects that may over time have distal impact on teachers and students. Teacher initiated echo effects, for example, may be an instance in dialogue of the reflexive work that students are engaging in interviews. For example, a teacher solicits participation and this moment provides a data point with which to notice the consequence of the interaction. Student participation later in the discussion, unsolicited, may be the proximal impact of these teacher initiations and the reflexive work that they may prompt. These moments may have a more distal impact as well, i.e., across lessons, across time. However, one of the limitations of the present study is that the observational data is cross sectional. Therefore, it is not possible to examine the reach of these moments, how they accumulate over time within a case. Nevertheless, the proximal impact that the echo effects have on students' participation, and the reflexive work that student narratives elucidate, suggests that salient moments of this kind may be particularly pivotal for students who usually sit on the margins of discussion.

These findings point to the particularly important role that teachers can play to foster students' sense of agency and enactment thereof in dialogic class discussions, especially with respect to students that rarely participate. Teachers can mark the kinds of contributions that are valued you in the dialogic classroom, support students in recognizing that talk is a form of learning and that all contributors can be positioned as a resource for learning. We believe this may be particularly important in reform classrooms, like dialogic pedagogy, where new pedagogical approaches and cultures of learning are being introduced, and teachers as well as students may well need support in taking up these new forms of teaching and learning.

Teachers' authority in the classroom can be leveraged to support more distributed opportunities for students to engage in whole class discussions. Mehan (1979) introduced the field to ubiquitous structure of I-R-E in classroom talk, and we still find glimmers of this in the exchange structure in this data (teacher solicitations). While the dialogic classroom may shift this authority with respect to the domain knowledge construction, the teachers' role in what happens in classroom learning is still prevalent aspect of institutional structure of school and classroom learning. We propose that this authority over who-speaks-when can be leveraged for the purposes of distributing more widely learning opportunities through talk. This is a small modification in the way that teachers facilitate discussions that may generate particularly high yield with respect to student agency, as it can create affordances for students on the margins of discussions to 
enact agency. In the present study we do see evidence in high contributors' narratives that Mr. Stanley does, at times, make moves to curb high contributors' over-participation. However, our observation data provides little evidence that this teacher is making a concerted effort to involve low contributors in discussions. However, our findings also point to the dynamic nature of agency in this kind of learning activity. Student-initiated echo effects may have an impact on the way in which teachers elicit contributions and make sense of what students can do in talk. Students' action may prompt teachers to reflect on the kind of contributions that students can make and subsequently the kind of opportunities for sensemaking they provide for these students in talk. Zohar (2004) found that some teachers did not think that the cognitive demand for argumentation was appropriate for low performing students, which may have an impact on how teachers facilitate discussions. If teachers notice what students can accomplish in talk and that they can engage in cognitively demanding science discussions, they may provide more of these opportunities for students. Thus, disrupting a culture of low expectations.

We see evidence of such a shift in an earlier study (Clarke et al, 2013). In this study, students participated in computer supported collaborative learning (CSCL) in small groups without their teacher. When students rejoined their teacher the following day for an Accountable Talk discussion on the same topic, the teachers' facilitation qualitatively raised the cognitive demand in these discussions. We interpreted this difference in the teachers' facilitation of discussion as the teachers' response to students' agency in when they joined this discussion prepared through their CSCL group work. While we found that this effect did not persist, we observed it every time students participated in the CSCL activities. Thus, we observed this effect 8 times over the course of two years, with this teacher's five different classes respectively. Thus, we argue that students can have an enabling effect on how teachers facilitate discussions.

Overall, this study helps to contribute to an understanding of students' participation in dialogic class discussions, in particular marginal participation. It helps to show the dynamic and emergent nature of agency in learning through discussion. In doing so, it provides some insights into how teachers might support more equitable participation in class discussions so that all students might benefit in terms of the learning outcomes research shows academically productive dialogue helps to foster.

\section{Acknowledgements}

This research was sponsored by the National Science Foundation Award SBE-0836012 to the Pittsburgh Science of Learning Center. Many thanks to the reviewers and Jim Greeno for their comments on the earlier draft of this paper. As well as thanks to mentors and colleagues Edmund W. Gordon, Ana Mari Cauce, Catherine Voulgarides and Trenton Marsh for critical readings and discussions that lead to this work. Many thanks to James Woods and Catherine Stainton for their instrumental assistance with data collection and analysis.

\section{References}


Adamson, D., Dyke, G., Jang, H., \& Rosé, C. P. (2014). Towards an agile approach to adapting dynamic collaboration support to student needs. International Journal of Artificial Intelligence in Education, 1-33.

Asterhan, C. S. C., \& Schwarz, B. B. (2007). The effects of monological and dialogical argumentation on concept learning in evolutionary theory. Journal of Educational Psychology, 99(3), 626.

Asterhan, C. S. C., \& Schwarz, B. B. (2009). The role of argumentation and explanation in conceptual change: Indications from protocol analyses of peer-to-peer dialogue. Cognitive science, 33(3), 374-400.

Azmitia, M., \& Montgomery, R. (1993). Friendship, transactive dialogues, and the development of scientific reasoning. Social Development, 2(3), 202-221.

Bandura, A. (1989). Human agency in social cognitive theory. American psychologist, 44(9), 1175.

Bandura, A. (2006). Toward a psychology of human agency. Perspectives on psychological science, 1(2), 164-180.

Barton, A. C., \& Tan, E. (2010). We Be Burnin'! Agency, identity, and science learning. The Journal of the Learning Sciences, 19(2), 187-229.

Berkowitz, M. W., \& Gibbs, J. C. (1983). Measuring the developmental features of moral discussion. Merrill-Palmer Quarterly, 29(4), 399-410.

Berland, L. K., \& Reiser, B. J. (2009). Making sense of argumentation and explanation. Science Education, 93(1), 26-55.

Black, L. (2009). Differential participation in whole-class discussions and the construction of marginalised identities. The Journal of Educational Enquiry, 5(1).

Bourdieu, P. (1991). Language and Symbolic Power. Cambridge: Harvard University Press.

Cauce, A. M., \& Gordon, E. W. (2012). Toward the Measurement of Human Agency and the Disposition to Express It. In G. Commission (Ed.), Gordon Commission on the Future of Educational Assessment. Princeton: Educational Testing Service.

Chi, M. T. (2009). Active-constructive-interactive: A conceptual framework for differentiating learning activities. Topics in Cognitive Science, 1(1), 73-105.

Chi, M. T., \& Roscoe, R. D. (2002). The processes and challenges of conceptual change Reconsidering conceptual change: Issues in theory and practice (pp. 3-27): Springer.

Chin, C., Brown, D. E., \& Bruce, B. C. (2002). Student-generated questions: A meaningful aspect of learning in science. International Journal of Science Education, 24(5), 521-549.

Chin, C., \& Osborne, J. (2010). Students' questions and discursive interaction: Their impact on argumentation during collaborative group discussions in science. Journal of Research in Science Teaching, 47(7), 883-908.

Clarke, S. N. (2015). The Right to Speak. In L. B. Resnick, C. S. C. Asterhan \& S. N. Clarke (Eds.), Socializing Intelligence through Academic Talk and Dialogue. Washington, DC: American Educational Research Association.

Clarke, S. N., Chen, G., Stainton, C., Katz, S., Greeno, J. G., Resnick, L. B., . . Rosé, C. P. (2013). The Impact of CSCL Beyond the Online Environment. In N. Rummel, M. Kapur, M. Nathan \& S. Puntambekar (Eds.), To See the World and a Grain of 
Sand: Learning across Levels of Space, Time, and Scale: CSCL 2013 (Vol. 1, pp. 105-112). Madison, WI: International Society of the Learning Sciences.

Clarke, S. N., Resnick, L. B., \& Rosé, C. P. (2015). Dialogic Instruction: A New Frontier. In L. Corno \& E. M. Anderman (Eds.), Handbook of Educational Psychology (3rd ed.). New York: Routledge.

Driver, R., Newton, P., \& Osborne, J. (2000). Establishing the norms of scientific argumentation in classrooms. Science Education, 84(3), 287-312.

Felton, M., \& Kuhn, D. (2001). The development of argumentive discourse skill. Discourse Processes, 32(2-3), 135-153.

Fischer, F., Kollar, I., Mandl, H., \& Haake, J. M. (Eds.). (2007). Scripting ComputerSupported Collaborative Learning (Vol. 6). New York: Springer.

Fuchs, L. S., Fuchs, D., Hamlett, C. L., Phillips, N. B., Karns, K., \& Dutka, S. (1997). Enhancing students' helping behavior during peer-mediated instruction with conceptual mathematical explanations. The Elementary School Journal, 223-249.

Gee, J. (1985). The Narrativization of Experience in the Oral Style. Journal of Education, 167(1), 9-35.

Giddens, A. (1984). The constitution of society: Outline of the theory of structuration: University of California Press.

Goffman, E. (1959). The Presentation of Self in Everyday Life. New York: Anchor Books.

Herrenkohl, L. R., \& Guerra, M. R. (1998). Participant structures, scientific discourse, and student engagement in fourth grade. Cognition and Instruction, 16(4), 431473.

Howe, C. (2010). Peer dialogue and cognitive development: A two-way relationship? In K. Littleton \& C. Howe (Eds.), Educational dialogues: understanding and promoting productive interaction. London: Routledge.

Howe, C., \& McWilliam, D. (2001). Peer Argument in Educational Settings Variations Due to Socioeconomic Status, Gender, and Activity Context. Journal of Language and Social Psychology, 20(1-2), 61-80.

Howe, C., Tolmie, A., Thurston, A., Topping, K., Christie, D., Livingston, K., . . . Donaldson, C. (2007). Group work in elementary science: Towards organisational principles for supporting pupil learning. Learning and Instruction, 17(5), 549563.

Hutchby, I., \& Wooffitt, R. (2008). Conversation analysis (2nd ed.). Cambridge ; Malden, MA: Polity.

Kelly, S. (2007). Classroom discourse and the distribution of student engagment. Social Psychology of Education, 10, 331-352.

Kelly, S. (2008). Race, social class, and student engagement in middle school English classrooms. Social Science Research, 37, 434-448.

King, A. (1992). Facilitating elaborative learning through guided student-generated questioning. Educational Psychologist, 27(1), 111-126.

King, A. (1999). Discourse patterns for mediating peer learning. In A. M. O'Donnell \& A. King (Eds.), Cognitive perspectives on peer Learning. Mahwah, NJ: Lawrence Erlbaum. 
King, A., \& Rosenshine, B. (1993). Effects of guided cooperative questioning on children's knowledge construction. The Journal of experimental education, 61(2), 127-148.

Kruger, A. C. (1992). The effect of peer and adult-child transactive discussions on moral reasoning. Merrill-Palmer Quarterly (1982-), 191-211.

Kruger, A. C. (1993). Peer collaboration: Conflict, cooperation, or both? Social Development, 2(3), 165-182.

Labov, W., \& Waletzky, J. (1967). Narrative Analysis: Oral Versions of Personal Experience. Paper presented at the Essays on the Verbal and Visual Arts: Proceedings of the 1966 Annual Spring Meeting of the American Ethnological Society, Philadelphia.

Littleton, K., \& Howe, C. (2010). Educational dialogues: understanding and promoting productive interaction. London: Routledge.

McAdams, D. P. (2008). The life story interview. Retrieved March 30, 2011, from https://http://www.sesp.northwestern.edu/docs/LifeStoryInterview.pdf

Mehan, H. (1979). Learning lessons : social organization in the classroom. Cambridge, Mass.: Harvard University Press.

Mercer, N., Dawes, L., Wegerif, R., \& Sams, C. (2004). Reasoning as a Scientist: Ways of Helping Children to Use Language to Learn Science. British Educational Research Journal, 30(3), 359-377.

Mugny, G., \& Doise, W. (1978). Socio-cognitive conflict and structure of individual and collective performances. European Journal of Social Psychology, 8(2), 181-192.

Nasir, N. i. S., \& Hand, V. (2008). From the court to the classroom: Opportunities for engagement, learning, and identity in basketball and classroom mathematics. The Journal of the Learning Sciences, 17(2), 143-179.

National Research Council. (2012). A Framework for K-12 Science Education: Practices, Crosscutting Concepts, and Core Ideas. Washington, DC: The National Academies Press.

Osborne, J. (2010). Arguing to Learn in Science: The Role of Collaborative, Critical Discourse. Science, 328(5977), 463-466.

Rainio, A. P. (2008). From resistance to involvement: Examining agency and control in a playworld activity. Mind, Culture, and Activity, 15(2), 115-140.

Rainio, A. P. (2009). Horses, girls, and agency: Gender in play pedagogy. Outlines. Critical Practice Studies, 11(1), 27-44.

Resnick, L. B., Asterhan, C. S. C., \& Clarke, S. N. (Eds.). (2015a). Socializing Intelligence through Academic Talk and Dialogue. Washington, DC: American Educational Research Association.

Resnick, L. B., Asterhan, C. S. C., \& Clarke, S. N. (2015b). Introduction: Talk, Learning and Teaching. In L. B. Resnick, C. S. C. Asterhan, \& S. N. Clarke (Eds.), Socializing Intelligence through Academic Talk and Dialogue (pp. 1-12). Washington, DC: American Educational Research Association.

Ricoeur, P. (1980). Narrative Time. Critical Inquiry, 7(1), 169-190.

Riessman, C. K. (1993). Narrative Analysis (Vol. 30). London: Sage Publications. 
Rosenshine, B., Meister, C., \& Chapman, S. (1996). Teaching students to generate questions: A review of the intervention studies. Review of Educational Research, 66(2), 181-221.

Sandoval, W. A. (2005). Understanding students' practical epistemologies and their influence on learning through inquiry. Science Education, 89(4), 634-656.

Slavin, R. (1987). Ability grouping and student achievement in elementary schools: A best-evidence synthesis. Review of Educational Research, 57(3), 293-336.

Teasley, S. D. (1997). Talking about reasoning: How important is the peer in peer collaboration? In L. B. Resnick, R. Säljö, C. Pontecorvo \& B. Burge (Eds.), Discourse, Tools and Reasoning: Essays on Situated Cognition (pp. 361-384). Berlin: Springer.

Veenman, S., Denessen, E., van den Akker, A., \& van der Rijt, J. (2005). Effects of a cooperative learning program on the elaborations of students during help seeking and help giving. American Educational Research Journal, 42, 115-151.

Webb, N. M. (1991). Task-related verbal interaction and mathematics learning in small groups. Journal for research in mathematics education, 366-389.

Webb, N. M., Franke, M. L., De, T., Chan, A. G., Freund, D., Shein, P., \& Melkonian, D. K. (2009). 'Explain to your partner': teachers' instructional practices and students' dialogue in small groups. Cambridge Journal of Education, 39(1), 49-70.

Webb, N. M., \& Mastergeorge, A. M. (2003). The development of students' helping behavior and learning in peer-directed small groups. Cognition and Instruction, 21(4), 361-428.

Webb, N. M., Troper, J. D., \& Fall, R. (1995). Constructive activity and learning in collaborative small groups. Journal of Educational Psychology,, 87, 406-423.

Zohar, A. (2004). Elements of teachers' pedagogical knowledge regarding instruction of higher order thinking. Journal of Science Teacher Education, 15(4), 293-312. 